Case report

\title{
Marjolin's ulcer: a challenging complication of non-healing wounds
}

\author{
Vitorino Modesto dos Santos ${ }^{1,2}$, Anna Gabriela Oliveira Camilo ${ }^{2}$, Leonardo Aquino de Souza ${ }^{2}$, \\ Lucas Maciel Rodrigues Monteiro ${ }^{2}$, Christiane Silveira Marinho ${ }^{2}$, Diogo Wagner da Silva de Souza ${ }^{2}$ \\ ${ }^{1}$ Catholic University Medical Course, Brasília-DF, Brazil \\ ${ }^{2}$ Armed Forces Hospital, Brasília-DF, Brazil
}

Received 15 March 2015, Accepted 18 April 2015

(C) 2015, dos Santos V.M., Camilo A.G.O., de Souza L.A., Monteiro L.M.R., Marinho C.S., da Silva de Souza D.W. (C) 2015, Russian Open Medical Journal

\begin{abstract}
Marjolin's ulcer is an uncommon malignant condition related to non-healing wounds, more often of burn injuries. Our aim is increase the suspicion index of primary care workers about the risk of squamous cell carcinoma in skin chronic ulcers or scar tissue, mainly in extremities. We report a Marjolin's ulcer associated with traumatic chronic ulcer in the leg of a 73-year-old white female. Histological diagnosis was poorly differentiated squamous cell carcinoma. The tumor evolved unsuspected on the border of the ulcer in a region of venous insufficiency and lymph edema. In the majority of cases, Marjolin's ulcer represents a highly aggressive squamous cell carcinoma. Adequate managing of risk factors constitutes the best tool for prevention of this malignancy, diagnosis is challenging, and it can be overlooked or under reported. As late diagnosis favors poor outcome, even single case reports might enhance the suspicion of primary care workers about this preventable condition.
\end{abstract}

Keywords: aged, carcinoma, squamous cell, etiology, skin ulcer, complications

Cite as dos Santos VM, Camilo AGO, de Souza LA, Monteiro LMR, Marinho CS, da Silva de Souza DW. Marjolin's ulcer: a challenging complication of nonhealing wounds. Russian Open Medical Journal 2015; 4: e0305.

Correspondence to Vitorino Modesto dos Santos. Address: Armed Forces Hospital, Estrada do Contorno do Bosque s/n, Cruzeiro Novo, 70658-900, BrasíliaDF, Brazil. Telephone: \#55-61 39662103. Fax: \#55-61 32331599. E-mail: vitorinomodesto@gmail.com

\section{Introduction}

The term Marjolin's ulcer (MU) involves diverse malignant tumors developing on the site of chronic skin wounds. This uncommon, frequently under-recognized, and ominous condition was first described in 1828 [1-4]. Physiopathology of this entity is not well understood, but predisposing factors include genetics, local trauma and lacerations, chronic venous stasis, and inflammatory conditions (e. g. pressure ulcers, fistulas, and hansenic ulcers) [1-10]. Enhanced pain, malodorous exudates, bleeding, and vegetations suggest a malignant change $[1,3,6,8]$. $\mathrm{MU}$ is an aggressive tumor, developing insidiously and with a high rate of regional metastasis $[1-5,8]$. The most common cell type of tumor found in association with $\mathrm{MU}$ is a squamous cell carcinoma $[1,4,8-10]$. A high suspicious index is necessary to diagnose skin tumors arising in patients with burn scars or chronic ulcers $[1,5]$. Worth of note, multiple superficial and deep biopsies should be done in all suspected lesions, in order to accurately rule out the presence of $\mathrm{MU}[1,3,5,8]$. The treatment of choice is radical resection with skin grafting $[1,5]$; while lymph node dissection is not consensual $[1,4,8]$. Because of the guarded prognosis, proper care of chronic ulcers constitutes the best preventive tool $[1,7]$.

The objective of the authors is to enhance the suspicion index of primary care workers about this uncommon, but ominous condition.

\section{Case report}

A 73-year-old white woman from rural area, with past medical history of hypertension, diabetes, metabolic syndrome, atrial fibrillation and congestive heart failure, was admitted to our hospital because of an infected vegetating lesion on the anterior lateral region of her left lower limb. Thirty-five years before admission, she suffered an automobile accident with severe contusion on the left leg, over a site of chronic venous insufficiency and lymph edema, with resultant non-healing wound and areas of irregular scarring. One year before admission, she had observed the progressive development of a painless vegetating mass on the border of the ulcer. More recently, local pain, bleeding, and necrotic and inflammatory changes (Figure 1) with foul odor occurred. An Echo-Doppler study of the lower limbs revealed bilateral dilation of the arch of the great saphenous vein, with blood reflux to the collateral veins, more evident in the left lower extremity. After various unsuccessful courses of antibiotic therapy and inconclusive superficial skin biopsies (compatible with venous insufficiency), she was admitted to our hospital.

On admission, she had no fever. Her BMl was $31 \mathrm{~kg} / \mathrm{m} 2$, blood pressure $130 / 70 \mathrm{mmHg}$, and heart rate $72 \mathrm{bpm}$. Inguinal lymph nodes were not remarkable. Laboratory data (normal ranges): hemoglobin $11.7(11.1-16.1) \mathrm{g} / \mathrm{dl}$, hematocrit 36.9 (39-53) \%, white cells 8.76 (4.011.0) $\times 10^{3} / \mathrm{mm}^{3}$, platelets $227(150-450) \times 10^{3} / \mathrm{mm}^{3}$, erythrocyte sedimentation rate (ESR) $18(\leq 15) \mathrm{mm} /$ hour, glucose 112 (70-99) $\mathrm{mg} / \mathrm{dl}$, urea 38 (10-50) mg/dl, creatinine $0.8(0.7-1.3) \mathrm{mg} / \mathrm{dl}$, uric acid 
$4.4(2.6-6.0) \mathrm{mg} / \mathrm{dl}$, alanine aminotranferase (ALT) $14(<32) \mathrm{U} / \mathrm{l}$, aspartate aminotranferase (AST) $15(<39) \mathrm{U} / \mathrm{l}$, gamma glutamyl transpeptidase (GGT) $39(<55) \mathrm{U} / \mathrm{l}$, alkaline phosphatase $61(40-150)$ $\mathrm{U} / \mathrm{l}$, ionized calcium 1.30 (1.12-1.32) mmol/l, magnesium $1.8(1.6-2.5)$ $\mathrm{mg} / \mathrm{dl}$, sodium 136 (136-145) mmol/l, potassium 5.0 (3.5-5.1) mmol/l; and urinalysis was normal. Chest X-ray images were unremarkable. Cultures of skin samples for microorganisms showed Escherichia coli.

This local infection was initially treated with ceftazidime, which was further changed for ciprofloxacin plus clindamycin. Furthermore, the tumor was removed, and the histopathology study of surgical samples revealed a poorly differentiated squamous cell carcinoma (Figure 2). The tumor was infiltrating the reticular dermis without vascular invasion, but involving the excisional margins. Marjolin's ulcer was then characterized, and the patient was referred to Oncology Division for specialized treatment, including neo adjuvant chemotherapy and rescue surgery with limb preservation.

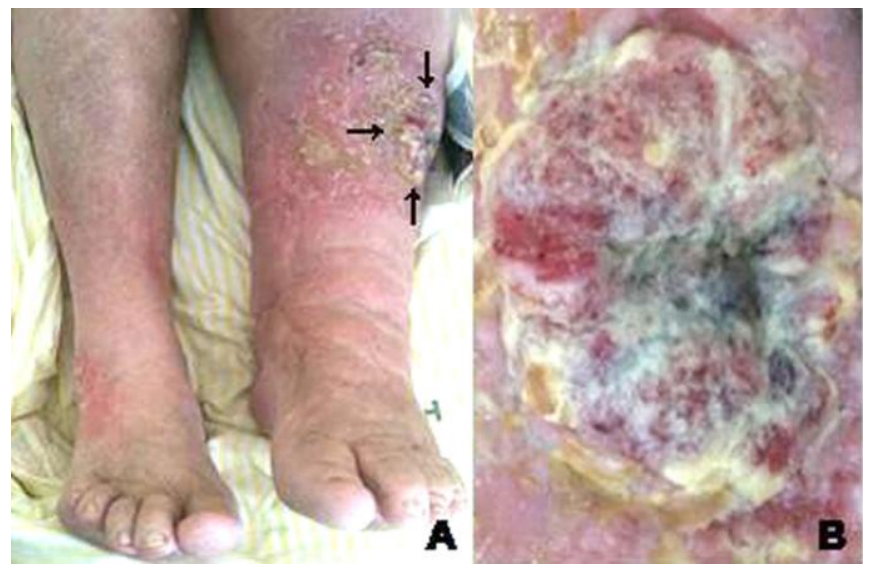

Figure 1. A: Chronic venous insufficiency and lymph edema on the left lower limb, and a large irregular ulcer (arrows) with inflammatory features and bleeding in the anterior lateral region; B: Conspicuous fungating mass, which developed on the border of a non-healing wound showed in detail.

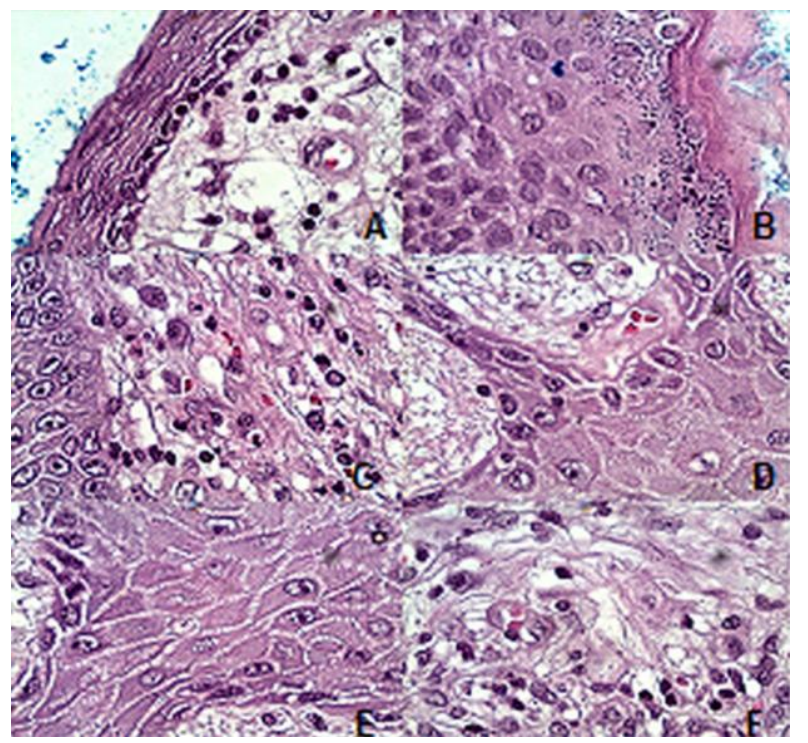

Figure 2. Photomicrography of the poorly differentiated invasive squamous cell carcinoma, in the border of a chronic ulcer in the left lower limb (HE, high magnification).

\section{Discussion}

Although the leading etiology of $\mathrm{MU}$ is a post-burn wound [1], this was not the cause in our patient. In fact, the woman described herein had suffered an accidental trauma on her left leg 35 years prior to this admission, which caused a venous wound evolving to a chronic cutaneous ulcer. Therefore, the etiologic factors of $\mathrm{MU}$ involved in the present case include toxins from tissue injury (trauma, inflammation, and infection) and insufficient drainage (venous and lymphatic) [1, 2, 5]. Average duration of chronic malignant changes in $\mathrm{MU}$ is 35 years $[1,2,4]$, similar to the present report; on the contrary of the acute type of $\mathrm{MU}$, which develops in a period inferior to one year $[1,2]$.

Differential hypotheses in the present case included pseudo epitheliomatous hyperplasia, basal cell carcinoma, melanoma, sarcomas, hanseniasis, leishmaniasis, mycosis, syphilis, tuberculosis, mycobacteriosis, filariasis, among others [1]. However, the search for mycobacteria, treponema, fungi, protozoa and other parasites was negative in samples from the cutaneous biopsies performed in multiple sites. Histological studies characterized a MU due to a poorly differentiated squamous cell carcinoma; a different finding from the majority of MU cases, which are due to moderate or well-differentiated types $[1,10]$. However, MU related to trauma and venous insufficiency is often reported in lower limbs [6-9]. The leg ulcer of our patient showed classical signs and symptoms indicative of malignant change (pain, crusting, bleeding, increase in size and in consistence, vegetation, and foul exudation) $[1,6,7]$. Nevertheless, previous skin biopsies were not deep enough and were performed on single sites, differing from the recommended procedures that can increase the accuracy of this diagnosis [8]. Worthy of note, more aggressive courses of squamous cell carcinoma and more frequent metastases occur in MUs affecting the lower extremities, and with late diagnoses $[1,4]$.

Tiftikcioglu et al. found both postoperative regional (40.3\%) and late pulmonary (41.9\%) metastases among 62 individuals with diagnosis of $\mathrm{MU}$ arising on the extremities, and the estimated average time of survival in the studied group was 7.76 years [4]. Interestingly, in the above mentioned study the female: male ratio was 2:1, the latency time was 35.9 years, and the mean age was 48 years; however, all the MUs developed in old burn scars. Bauk et al reviewed 12 cases of $\mathrm{MU}$ predominantly $(75 \%)$ in the lower limbs of Brazilian patients aging from 38 to 86 years (mean age of $61.3 \pm 16.9$ years), and $41.7 \%$ were female. The latency period ranged from 10 to 50 years, with mean time of $23.7 \pm 14.5$ years). Amputation occurred in $66.7 \%$ of the cases, and 2 patients were submitted to tumor excision [8]. Chalya et al reviewed 56 patients with MU in Tanzania and found a male: female ratio approximately $2: 1$, mean latent time of $11.34 \pm 6.14$ years between the initial lesion and the final diagnosis, predominant site of lesions in lower limbs (near $43 \%$ ), and over than $91 \%$ of the cases were squamous cell carcinomas. Worthy of note, lymph node and distant metastasis (respectively near $32 \%$ and $27 \%$ ) were found at time of diagnosis, with about $7 \%$ of mortality [1].

\section{Conclusion}

MUs include diverse malignancies arising at the site of burn scars or non-healing chronic wounds. Because of the low suspicion index, this challenging entity can follow under diagnosed. Moreover, late diagnoses frequently pose an adverse burden on the management and prognosis. The present report aims to 
enhance the awareness of primary care workers about this preventable condition, emphasizing the role played by early diagnosis and prompt surgical procedures on the final outcomes of patients with MUs.

Conflict of interest: None to be declared.

\section{References}

1. Chalya PL, Mabula JB, Rambau P, Mchembe MD, Kahima KJ, Chandika $A B$, et al. Marjolin's ulcers at a university teaching hospital in Northwestern Tanzania: a retrospective review of 56 cases. World J Surg 2012; 10: 38. (PMID: 22336561) (doi: 10.1186/1477-7819-10-38)

2. Copcu E. Marjolin's ulcer: a preventable complication of burns? Plast Reconstr Surg 2009; 124(1): 156e-164e. (PMID: 19568055) (doi: 10.1097/PRS.0b013e3181a8082e)

3. Ogawa B, Chen M, Margolis J, Schiller FJ. Marjolin's ulcer arising at the elbow: a case report and literature review. Hand 2006; 1: 89-93. (PMID: 18780031) (doi: 10.1007/s11552-006-9007-1)

4. Tiftikcioglu YO, Ozek C, Bilkay U, Uckan A, Akin Y. Marjolin ulcers arising on extremities. Ann Plast Surg 2010; 64(3): 318-320. (PMID: 17042239) (doi: 10.1097/SAP.0b013e3181a73064)

5. Pavlovic S, Wiley E, Guzman G, Morris D, Braniecki M. Marjolin ulcer: an overlooked entity. Int Wound J 2011; 8(4): 419-424. (PMID: 21585661) (doi: 10.1111/j.1742-481X.2011.00811.x)

6. Agale SV, Kulkarni DR, Valand AG, Zode RR, Grover S. Marjolin's ulcer a diagnostic dilemma. J Assoc Physicians India 2009; 57: 593-594. (PMID: 20209721)

7. Asuquo ME, Ikpeme IA, Ebughe G, Bassey EE. Marjolin's ulcer: sequelae of mismanaged chronic cutaneous ulcers. Adv Skin Wound Care 2010; 23(9): 414-416. (PMID: 20729647) (doi: 10.1097/01.ASW.0000383211.18782.2a)

8. Bauk VOZ, Assunção AM, Domingues RF, Fernandes NC, Maya TC, Maceira JP. Úlcera de Marjolin: relato de 12 casos. An Bras Dermatol 2006; 81(4): 355-358.

9. Bozkurt M, Kapi E, Kuvat SV, Ozekinci S. Current concepts in the management of Marjolin's ulcers: outcomes from a standardized treatment protocol in 16 cases. J Burn Care Res 2010; 31(5): 776-780. (PMID: 20661151) (doi: 10.1097/BCR.0b013e3181eed210)

10. Combemale $P$, Bousquet $M$, Kanitakis J, Bernard $P$, Angiodermatology Group, French Society of Dermatology. Malignant transformation of leg ulcers: a retrospective study of 85 cases. J Eur Acad Dermatol Venerol 2007; 21(7): 935-941. (PMID: 17659003) (doi: 10.1111/j.14683083.2006.02118.x)

Authors:

Vitorino Modesto dos Santos - MD, PhD, Professor of Internal Medicine, Catholic University and Armed Forces Hospital, Brasília-DF, Brazil.

Anna Gabriela Oliveira Camilo - MD, Internal Medicine, Armed Forces Hospital, Brasília-DF, Brazil.

Leonardo Aquino de Souza - MD, Internal Medicine, Armed Forces Hospital, Brasília-DF, Brazil.

Lucas Maciel Rodrigues Monteiro - MD, Internal Medicine, Armed Forces Hospital, Brasília-DF, Brazil.

Christiane Silveira Marinho - MD, Internal Medicine, Armed Forces Hospital, Brasília-DF, Brazil.

Diogo Wagner da Silva de Souza - MD, Internal Medicine, Armed Forces Hospital, Brasília-DF, Brazil. 